\title{
Upaya Mengurangi Volume Minyak Flushing Produk TBHQ Selama Pergantian Produk Di Mesin Kombinator 3 Pt Asianagaro Agung Jaya Menggunakan Metode PDCA
}

\author{
Annisa Mulia Rani, Dede Mulyana \\ Fakultas Teknik Universitas Muhammadiyah Jakarta, Jalan Cempaka Putih Tengah, Kota Jakarta Pusat, DKI \\ Jakarta 10510, Indonesia \\ zc.annisa@gmail.com, dedemulyana200487@gmail.com.
}

\begin{abstract}
Abstrak
PT Asianagro Agung Jaya terletak adalah perusahaan pengolahan kelapa sawit dan memproduksi makanan. Dengan varian minyak goreng, margarine dan shorthening. Semakin meningkatnya kapasitas produksi di PT Asianagro Agung Jaya, maka semakin meningkat pula pengawasan dan pengendalian terhadap kualitas. Shorthening adalah salah produk yang komoditinya tinggi. Didalam shorthening terdapat bahan antioksidan yaitu TBHQ yang sifatnya sukar untuk dihilangkan. Shorthening di produksi di mesin Kombinator 3, tidak hanya shorhening yang di produksi di mesin kombinator 3 melainkan margarine. Shorthening adalah minyak padat yang didalamnya mengandung antioksidan. Oleh karena itu setiap pergantian produk dari shorthening ke margarin membutuhkan flushing atau pencucian jalur agar produk setelah shorthening tidak terkontaminasi. Volume flushing dibutuhkan 4 Metrik Ton dengan waktu 2 jam 4 menit. Hal itu yang menjadi masalah perusahaan dikarenakan standar perusahaan untuk volume flushing hanya 1,7 Metrik Ton dan waktu yang dibutuhkan 50 menit. Berdasarkan data tersebut menunjukan bahwa tingginya volume flushing dan waktunya cukup lama.

Metode yang digunakan untuk memecahkan masalah tersebut adalah dengan menggunakan metode PDCA (Plan, Do, Check, Action). Melalui kegiatan Quality Control Circle agar diperoleh informasi - informasi dari hasil diskusi yang dapat membantu memecahkan masalah tersebut. Pengumpulan data diperoleh dari dokumen perusahaan.

Hasil penelitian ini adalah menurunkan volume flushing artinya upaya perbaikan yang dilakukan untuk menurunkan volume flushing dan waktu waktu flushing hingga sesuai dengan standar perusahaan. Setelah perbaikan dilakukan diperoleh hasil bahwa volume flushing sekarang menjadi 1,7 Metrik Ton sesuai dengan standar perusahaan dan waktu yang dibutuhkan menjadi 90 menit. Walaupun untuk penurunan waktu flushing tidak sesuai dengan yang diharap yang artinya masih jauh dari standar perusahaan tetapi mengalami penurunan.
\end{abstract}

Kata kunci:

Flushing, shorthening, TBHQ, Antioxidant, Plan Do Check Action

\section{PENDAHULUAN}

Asianagro Agungjaya (AAJ) yang terletak di Jalan Semarang Blok A-6 No 1, KBN-Marunda, Jakarta Utara 14150. Telp 021-440259, merupakan salah satu perusahaan yang terdapat dalam Apical
Group Ltd. AAJ adalah perusahaan yang bergerak dalam pengolahan CPO (Crude Palm Oil).

Apical Group Ltd menghasilkan produk-produk berbahan dasar palm oil diantaranya, yaitu Minyak goreng 
(kemasan dan curah), Margarine (sachet dan karton untuk skala industri), shorthening (margarine putih) dan juga memproduksi bahan baku seperti powder fat untuk pakan ternak dan juga HPS Flakers (Hydrogenated Palm Stearin) untuk bahan baku lilin. Selain itu, memproduksi juga CNO (Coconut oil) yang berasal dari buah kelapa untuk bahan baku krimer.

Setiap produk yang dibuat menggunakan bahan baku yang berbeda dan juga bahan additive atau bahan tambahan yang berbeda pula. Oleh karena itu perlakuan proses setiap produk berbedabeda. Terdapat tiga buah mesin kombinator (kombinator 1, 2 dan 3) untuk membuat produk shorthening dan margarin. Mesin kombinator satu dan dua semi otomatis sedangkan untuk kombinator 3 sudah otomatis prosesnya, selain itu kapasitas yang dihasilkan lebih tinggi sekitar 189 MT (metrik ton) maksimal per hari. Untuk proses produksi shorthening dan margarin yang mengandung bahan TBHQ (tersier butil hidroquinon)/bahan tambahan biasanya menggunakan mesin kombinator tiga, melihat dari kapasitasnya yang lebih tinggi, karena untuk produk yang mengandung bahan TBHQ (tersier butil hidroquinon) tergolong produk yang banyak dipesan. TBHQ (tersier butil hidroquinon) ialah suatu bahan antioksidan kimiawi yang ditambahkan kedalam produk shorthening agar bisa bertahan lebih lama.

Setiap pergantian produk dari shorthening (yang mengandung TBHQ) ke produk lainnya (margarine) yang akan diproduksi di mesin kombinator 3 harus melalui flushing terlebih dahulu, agar produk selanjutnya tidak terkontaminasi dengan TBHQ. Proses flushing yaitu proses pencucian jalur/pipa dengan cara mengalirkan minyak agar pipa bersih dari antioksidan agar produk berikutnya tidak terkontaminasi. Proses flushing saat ini menggunakan 4 metrik ton minyak dengan waktu yang cukup lama yaitu 2 jam 7 menit.

Masalah terbesar ialah ketika Pergantian produk dari produk yang mengandung TBHQ (A) ke produk yang tidak mengandung TBHQ (B) memerlukan waktu flushing (minyak pencuci jalur pipa) yang sangat lama dan kuantiti minyak flushing yang digunakan cukup banyak. Hal tersebut yang menjadi masalah karena tidak sesuai dengan standar perusahaan yaitu volume flushing 1,7 metrik ton dengan waktu flushing 60 menit.

Dapat dilihat dari grafik diatas bahwa frequensi pergantian produk untuk TBHQ lebih banyak dari produk yang lain selama bulain Maret hingga Agustus.

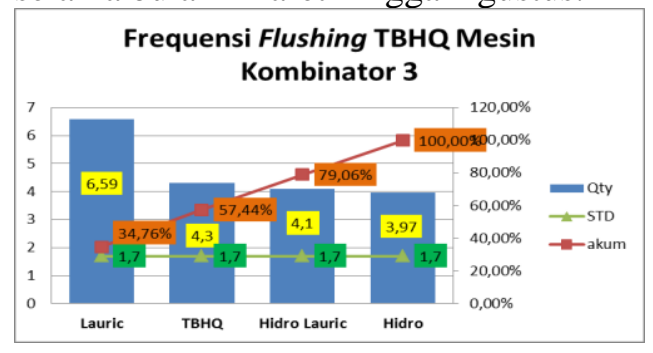

Gambar 1. Diagram Pareto Freq. Flushing Produk TBHQ dan Non TBHQ

Berdasarkan diagram pareto diatas dapat dijelaskan bahwa angka paling tinggi ditunjukan oleh produk lauric, namun dalam kasus ini yang akan diteliti oleh peneliti yaitu produk TBHQ. Dikarenakan produk TBHQ frequensi pergantian produknya sangat tinggi/order lebih tinggi dibandingkan dengan produk lainnya. Sehingga perbaikan harus cepat dilakukan untuk produk TBHQ dikarenakan berpengaruh terhadap keuntungan perusahaan. Untuk produk lauric, Hydro-lauric, dan juga hydro tidak memungkinkan untuk dilakukan perbaikan dikarenakan harus mengubah instalasi jalur pipa sendiri yang membutuhkan biaya sangat besar, hal tersebut tidak seimbang dengan margin yang diperoleh dari penjualan produk tersebut (frequensi order sangat kecil).

Berikut adalah grafik volume dan waktu rata-rata flushing per bulan, dimulai dari bulan Maret sampai Agustus 2016. 


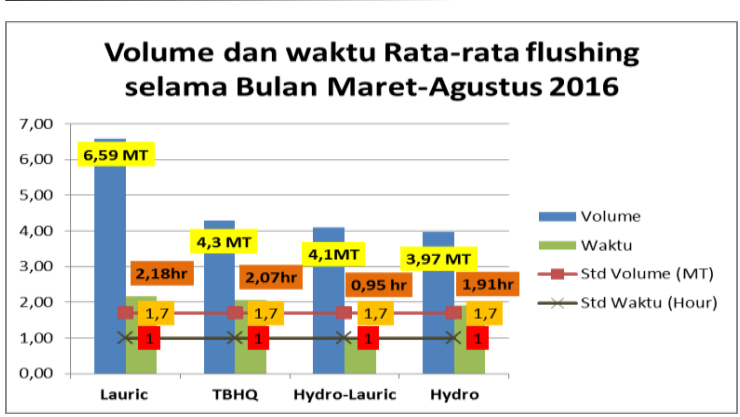

Gambar 2. Diagram Waktu Rata-rata Flushing Berdasarkan volume dan waktu yang dibutuhkan untuk flushing pada product yang mengandung TBHQ rata-rata pada periode Maret - Agustus 2016 sebesar 4,3 MT (metrik ton) dan memerlukan waktu selama 2 jam 7 menit.

Jelas terlihat bahwasanya volume dan waktu flushing jauh lebih besar dari standar perusahaan. Jika dibiarkan hal tersebut bisa menimbulkan kerugian pada perusahaan. Dikarenakan minyak flushing dengan volume tinggi akan menjadi reject/downgrade dan juga waktu flushing yang cukup lama dapat menghambat produksi produk lain. Selain itu menurunkan EBITDA (earning before interest, tax, depreciation and amortization). Adapun kerugian yang diterima perusahaan apabila hal tersebut diatas terus berlanjut. Berikut adalah perhitungan estimasi cost kerugian yang diterima perusahaan:

\begin{tabular}{|l|l|}
\hline Volume rata-rata flushing & $: 4,3 \mathrm{MT}$ \\
\hline Waktu rata-rata flushing & $: 2$ jam 4menit \\
\hline Harga rata-rata shorthening & $:$ USD 651/ton \\
\hline Harga rata-rata downgrade to CPO & $:$ USD 445.5/ton \\
\hline Standar flushing Perusahaan & $: 1,7 \mathrm{MT}$ \\
\hline
\end{tabular}

Kerugian jika volume setiap flushing melebihi standar perusahaan yaitu sebesar 2,6MT, maka$$
=\quad(4,3 \mathrm{MT}-2,6 \mathrm{MT}) \mathrm{X}(\mathrm{USD} \quad 651-\quad \text { USD }
$$

445,5)/MT

$=$ USD 349, 4

Kerugian jika waktu setiap change produk melebihi waktu standar perusahaan yaitu 60 menit, maka:

$=(2$ jam 4 menit -60 menit $) X$ 7MT/60 Menit XUSD 25 (Asumsi margin shorthening di Kombinator -3)

= USD176

TOTAL = USD 525, 4 Change Over
Berdasarkan data diatas, maka perlu dilakukan analisa dan perbaikan dalam proses produksi agar menjadi ideal sesuai standar PT Asianagro Agung Jaya.

\section{METODOLOGI}

Adapun metodologi yang digunakan adalah seperti gambar dibawah ini

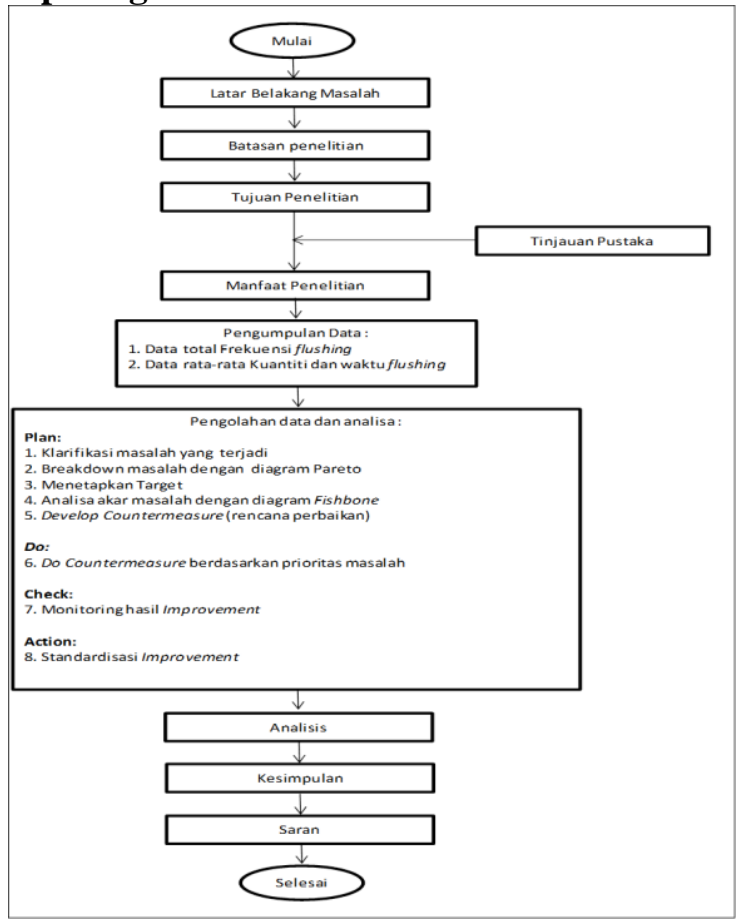

Gambar 3. Metodologi penelitian

Penelitian ini dilakukan di PT. Asianagro Agung Jaya diarea produksi (mesin kombinator 3) dan area laboratorium. Pertama-tama dilakukan metode brainstorming untuk mengetahui permasalahan yang terjadi dan langkah mana yang harus dilakukan terlebih dahulu. Setelah itu kita mendapatkan diagram fishbone. Penelitian ini menggunakan metode PDCA (plan, do, check, action).

\section{Hasil dan Pembahasan Pengumpulan Data}

Metode pengumpulan data yang akan digunakan adalah melakukan pengamatan langsung diperusahaan yang menjadi objek penelitian. Pengumpulan data pada penelitian ini, peneliti menggunakan dua data yaitu data total frekuensi flushing mesin kombinator 3 dan data rata-rata volume/kuantiti serta waktu flushing di mesin kombinator 3. Kemudian data tersebut diolah ditahap pengolahan data. 


\section{Pengolahan data}

Setelah data terkumpul selanjutnya diolah, pada pengolahan data disini menggunakan metode PDCA ( Plan, Do, Check , Action ) dan Pada tahap ini pula dilakukan analisa dan dibahas berdasarkan

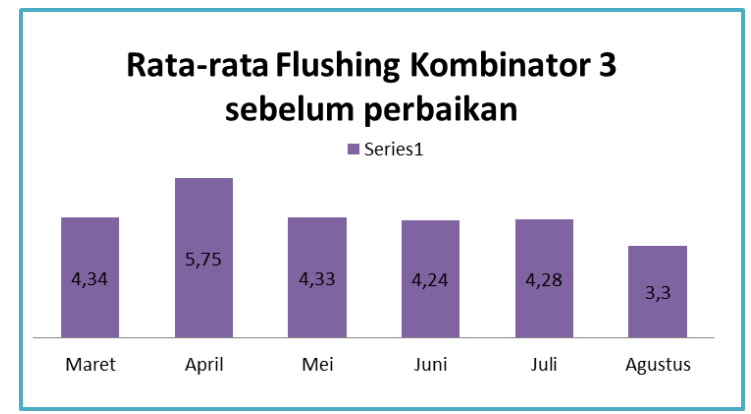

Gambar 4. Rata-rata flushing sebelum perbaikan mesin kombinator 3

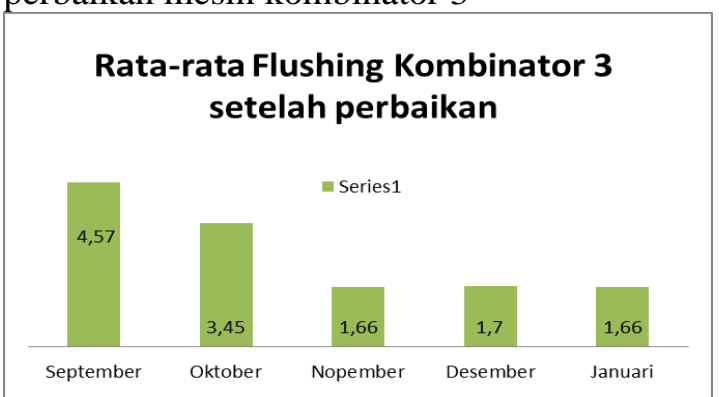

Gambar 5. Rata-rata flushing setelah perbaikan mesin kombinator 3

flushing MesinMengapa faktor mesin dapat menyebabkan volume flushing menjadi tinggi/besar?

Hot water system yang tidak stabil : sistem ini membantu sirkulasi panas pada pipa/ jalur untuk meluruhkan antioksidan yang menempel pada pipa, namun pada kenyataannya sistem ini kadangkala tidak stabil karena pada monitor menunjukkan $60^{\circ} \mathrm{C}$, sedangkan suhu aktual $90^{\circ} \mathrm{C}$. Jika suhu turun maka membutukan minyak untuk flushing lebih banyak.

$\checkmark$ Suhu tidak stabil (antara monitor dan aktual) disebabkan oleh pembacaan sensor suhu yang berada dalam pipa terhalang oleh fat/lemak yang membeku

$\checkmark$ Sebaiknya setelah penggunaan/produksi fat yang memilki titik leleh tinggi dilakukan pembersihan secara benar, hubungannya dengan rumusan masalah dan tujuan penelitian yang telah ditetapkan.

\section{HASIL DAN PEMBAHASAN}

Bedasarkan bab IV diperoleh data volume dan waktu flushing sebelum perbaikan. Sebagai berikut :

karena jika tidak dilakukan sensor suhu tidak dapat membaca suhu dengan benar

1. Improve Instrumen HPLC dan GC : selama ini sistem pengecekan TBHQ di lab menggunakan metode visual sehingga keakuratan kurang, sering kali analis mengatakan bahwa sampel masih terkontaminasi karena parameter titik akhir sampel TBHQ kurang jelas sehingga volume flushing ditambah lagi. Metode

Mengapa faktor metode dapat menyebabkan volume flushing menjadi tinggi/besar?

$\checkmark$ Standar TBHQ tidak ada : Volume flushing akan tinggi jikat tidak mempunyai standar TBHQ, karena bagian lab akan meminta flushing ulang.

$\checkmark$ Tidak ada WI pembuatan standar TBHQ

$\checkmark$ IK Flushing tangki mixing : volume flushing akan terus tinggi jika IK belum diperbaiki sesuai dengan improvment yang dilakukan.

$\checkmark$ Jalur pipa panjang: karena jarak antara tangki mixing dan mesin kombinator sangat jauh, menggunakan pipa spiral, lurus sangat jauh sehingga hal tersebut sangat berpengaruh terhadap volume flushing.

2. Man

Mengapa faktor man dapat menyebabkan volume flushing menjadi tinggi/besar?

$\checkmark$ Tidak ada marking jalur flushing, hal ini membuat operator tidak tahu mana prioritas

3. Material

Mengapa faktor material dapat menyebabkan volume flushing menjadi tinggi/besar?

$\checkmark$ Reagent yang expired atau larutan (campuran) kimia untuk analisa sampel TBHQ yang kurang fresh (lama) akan memberikan efek reaksi lebih lama sehingga analis lab tidak merelease hasil dan menyatakan sampel masih terkontaminasi 
$\checkmark$ Penyimpanan dan pengambilan larutan kimia (reagent) tidaka secara FIFO sehingga tanggal kadaluarsa tidak terkontrol.

4. Measurement

Mengapa faktor measurement dapat menyebabkan volume flushing menjadi tinggi/besar?

$\checkmark$ Analisa lab masih menggunakan metode qualitative sehingga keakuratan dalam penentuan sampel TBHQ terkontaminasi atau tidak rendah hal tersebut menyebabkan terjadinya flushing ulang.

$\checkmark$ Sisa fat/minyak pada tangki mixing sekitar $100 \mathrm{~kg}$ walaupun PLC/monitor menunjukkan sudah 0 hal ini karena sudah sistem yang disetting, oleh sebab itu sisaan fat tersebut otomatis di flushing lebih banyak.

Adapun peta kendali $\mathrm{C}$ sebelum dan sesudah adalah dibawah ini
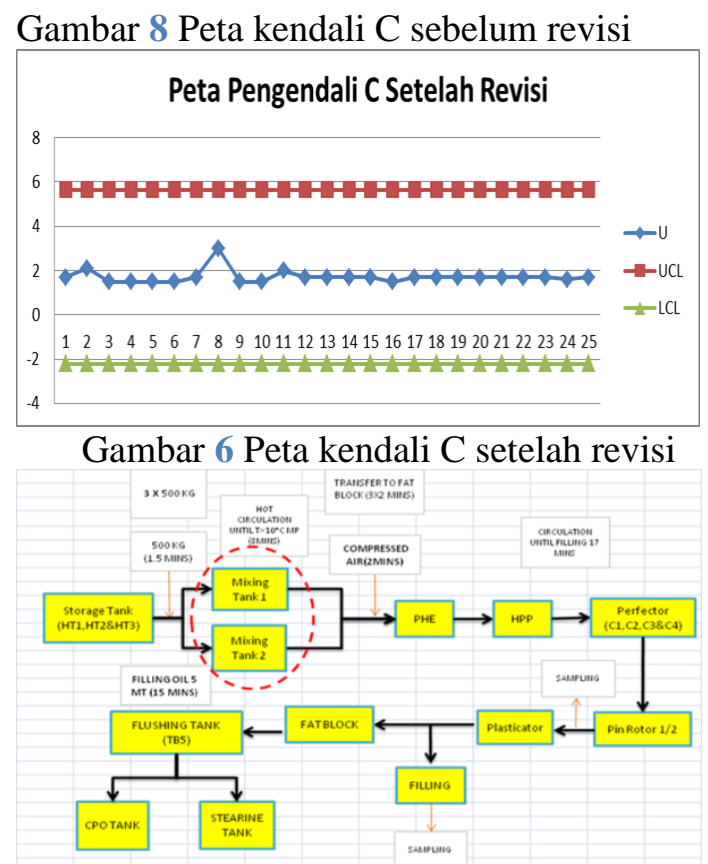

Gambar 7 SOP setelah perbaikan

Standardisasi diperlukan untuk mencegah timbulnya kembali masalah yang sama dikemudian hari Setelah standart ditetapkan, akan dilakukan monitoring pelaksanaannya dan sampai terjadinya perubahan standart kembali

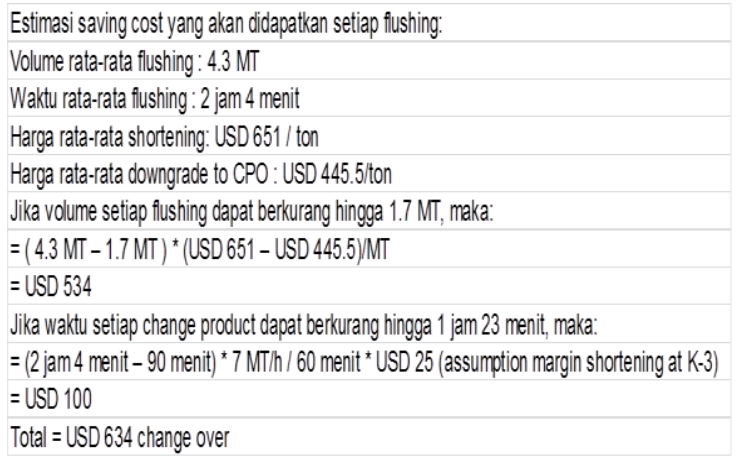

Dengan melihat perhitungan diatas, maka dapat dilihat bahwa ada penghematan sebesar USD 634 disetiap pergantian produk TBHQ.

\section{SIMPULAN DAN SARAN \\ Kesimpulan}

1. Upaya penurunan volume flushing berhasil sesuai dengan standar perusahaan yaitu sebesar 1,7 MT (metrik Ton) yang sebelumnya volume flushing mencapai 4 metrik ton lebih.

2. Terdapat penurunan dari sebelumnya 2 jam lebih menjadi 90 menit. Hal ini cukup membantu dalam upaya reduce cost pergantian produk.

3. Dengan adanya perbaikan maka EBITDA perusahaan meningkat, penghematan yang diperoleh dari setiap pergantian produk TBHQ yaitu sebesar USD 634.

\section{Saran}

Berdasarkan kesimpulan diatas dapat diberikan saran sebagai berikut :

1. Melihat dari hasil yang bisa dicapai dengan tahapan PDCA penulis berharap pihak perusahaan lebih mengembangkan lagi metode dan juga inisiatif karyawan agar mampu menyelesaikan reduce time untuk proyek ini, agar dapat meningkatkan keuntungan bagi perusahaan.

2. Baiknya dilakukan verifikasi metode SOP analisa laboratorium maupun SOP Flushing secara berkala.

\section{DAFTAR PUSTAKA}

Belitsz, H-D., 1999. Food Chemistry, second edition. Germany.

Catur Wahyuni, Hana, dkk., 2015. Pengendalian Kualitas. Cetakan pertama. Graha Ilmu, Yogyakarta.

Fakhri, Faiz Al. (2010). Analisis Pengendalian Kualitas Produksi di PT. Masscom 
Grahpy Dalam Upaya Mengendalikan

Tingkat Kerusakan Produk

Menggunakan Alat Bantu Statistik.

Universitas Dipenogoro : Tidak

diterbitkan.

Hart, Harold., 1990. Kimia Organik (suatu kuliah singkat). Edisi keenam. Alih bahasa : Dr. Suminar Acmadi Ph.D. Institut Pertanian Bogor. Erlangga, Jakarta.

Hicks, Philip E. Industrial Engineering and Management A New Perspective, Second Edition. New York: McGrawHill.

Kochhar, S.P dan Rossel, S.B. 1990. Detection, Estimation, and evaluation of Antioxidant in food system. Food Antioxidant. Elsevier Sci Publ Ltd. London, New York.

Nasution, M.N., 2005. Manajemen Mutu Terpadu (Total Quality Management) Edisi Kedua. Ghalia Indonesia, Bogor.

O'Brien, Richard., 2004. Fats and Oils Formulating and Processing for Applications. Second Editions. CRC Press, New York.

Pratt, D. E. 1992. Natural Antioxidant from Plant Material. Di dalam Huang, M. T., Ho, C. T. Dan Lee, C. Y. (eds). Effect on Healt II : Antioxidant and cancer Prevention. American Chem. Soc., Washington, DC.

Wahyu Ariani, Dorothea., 1999. Manajemen Kualitas. Cetakan pertama. Universitas Atma Jaya Yogyakarta.

Wignjosoebroto, Sritomo., 2006. Pengantar Teknik dan Manajemen Industri. Edisi pertama. Cetakan kedua. Institut Teknologi Sepuluh Nopember. 